\title{
COM LA INSEGURETAT DESAFIA EL SOCIOLEG
}

\author{
Renaud Dulong \\ (CRNS Parts)
}

Hom podrà llegit el text següent mogut per tres menes d'interès. Primerament, hom pot trobar interessant una primera esbrossada sociològica d'aquest terreny encara desconegut que és la inseguretat. Hom pot, a continuació, intertogat-se sobre el desnivell dels jocs de llenguatge que sepa. ten els discursos «politics» sobre la inseguretat $i$ les formulacions de la gent que afirma viute aquesta inseguretat. Per últim, hom pot sentir-se més aviat esperonat per la dimensió epistemològica del text, pels reptes que la insegutetat planteja a la sociologia, reptes que imposen la revisió de les formes de producció del discurs sociològic o, si més no, obliguen a haver d'anar amb compte amb els problemes que aquest discurs provoca. Aquestes tres lectures del text són legítimes en tant que ja estaven conscientment en la gènesi de la seva iedacció; malgrat tot, cal subratllar --perquè el text to el recull prou bé-- un quart punt del qual desitjaríem que en quedés la «lliçó»: que cap dels tres punts no hauria d'ésser pensat independentment dels altres dos."

1. El text segueix el de la conferència pronunciada el 27 de març de 1984 a 1'Associació Catalana de Sociologia de Barcelona, que alhora es basava en una argumentació desenvolupada una mica abans en tuna exposició feta a les trobades criminològiques de la Universitat de Louvain-la-Neuve (Bèlgica). 


\section{UN TERRENY SATURAT D'EXPLICACIONS}

La inseguretat planteja d'entrada problemes epistemològics al sociòleg perquè es presenta com una sociologia. Si deixem de banda - tot reservant la seva anàlisi per a un altre moment-- la relació que mantenen amb les pràctiques de protecció, els discursos sobre la inseguretat són discursos del tot sociològics. Si és legítim, en d'altres casos, proposar-se de construir l'objecte, de buscar les determinacions, de provar models, aquí l'objecte apareix ja amb la seva explicació, amb les seves explicacions... amb massa explicacions. Aquest és el particular repte que la inseguretat planteja al sociòleg, es tracta d'un domini ja saturat d'explicacions.

Per a demostrar-ho, passarem revista a alguna d'aquestes explicacions. Tot fent-ho, no farem pas una crítica de cadascuna d'elles, ja que cadascuna conté un graus de veritat, cadascuna constitueix un candidat vàlid per a explicar el fenomen. Però, d'una banda, cadascuna es presenta com a explicació definitiva; supera aleshores la seva pertinència per a explicar qualsevol cosa i esdevé sospitosa de pervertir aquesta explicació en recerca d'un cap de turc. D'altra banda, a més, i és aquí sobretot on es planteja el problema, la seva seriació produeix un efecte global d'equívoc. ${ }^{2}$

\subsection{L'EXPLICACIÓ PER LA DELINQÜÈnCIA}

La primera explicació de la inseguretat atribueix aquesta a la delinqüència. Evidentment no negarem que els delinqüents tenen alguna cosa a veure amb la inseguretat, però que aquests siguin la «causa» de la inseguretat és quelcom de dubtós. Una reducció com aquesta d'un fenomen respecte a un altre ensopega, si més no, amb un problema: com explicar que, abans que no es parlés d'inseguretat, ja hi havia delinqüència $i$, fins $i$ tot, una mena de delinqüència més perillosa? Explicar la inseguretat per l'augment de la delinquiència és induir uns raonaments molt dubtosos sobre els llindats de tolerància de la delinqüència que una població podria suportar, llindars més enllà dels quals es produiria el pànic.

Dient-ho d'una altra manera, podríem partir de la idea de l'existència d'un desnivell entre la inseguretat $i$ la delinquiencia, desnivell que ve accentuat per Ia referència a situacions més crítiques com les de Nova York o Bogotà, per no parlar de Belfast o Beirut. La inatge del desnivell o sepa-

2. Cf. Werner Ackermann, Renaud Ludong, Henti-Pjerre Jeudy: Imaginaires de İinsécurité. Libraitie des Méridiens, París, 1983. Capítol 1: \&Les equivoques de l'insécurité». 
ració és còmoda en tant que indueix la idea de mecanismes d'amplificació, mecanjsmes on conflueixen naturalment fenòmens simbòlics; tot i així, té una vessant enganyosa en tant que també suggereix que hi hauria una realitat delinqüent objectivament mesurable, cosa que, com veurem més endavant, és força discutible.

La inseguretat és una teacció davant de la delinquiència, però no és tan sols això. Posa en joc una simbologia -representacions, esquemes d'acció, màximes- que mereix d'ésser analitzada com a tal. La reducció de la inseguretat a la delinqüència és un procediment còmode, utilitzat sovint amb fins corporatius, per a eliminar el fenomen i substituir-lo per tot un altre seguit de qüestions.

\subsection{L'EXPLicació PER LA PREMSa, PELS MITJANS DE COMUNICACIó, PELS SONDEIGS D'OPINIÓ}

En aquest capítol els arguments avançats tampoc no són falsos. La inseguretat és mantinguda pels mitjans de comunicació. Anant més lluny: hom no ha començat a parlar de la inseguretat fins que la premsa no l'ha produida com a esdeveniment i no n'ha fornit, per sondeig, la mesura. Abans que els sondeigs d'opinio haguessin insctit la inseguretat en llurs qüestionaris d'enquesta, ningú no en parlava. Això legitima que ens interroguem sobre la possibilitat d'una fabricació de la inseguretat per part de la prernsa, fabricació que confirmaria el lloc que aquesta ha destinat des de sempre als successos: la premsa popular neix als segles xvrri i XIX amb les narzacions de crims i càstigs. ${ }^{3}$

Una tesi semblant ens remet al problema de la telació de la premsa amb el seu públic. Ens guardarem prou bé d'entrar en un debat que s'assembla força al de saber què va ésser primer si l'ou o la gallina. Només seria interessant assenyalar una nova reducció que oblitera també la simbologia, però aquesta vegada com a fenomen que la societat podria ésser capaç de produir per ella mateixa al matge dels mitjans oficials de comunicació.

\subsection{L'EXPLICACIÓ PER UNA VOLUNTAT POLÍTICA}

És una argumentació una trica diferent de la precedent $\mathrm{i}$ que disposa també d'una base històrica: a França, fou la campanya presidencial del 1974

3. Cf. Georges Auciair: Le Mana quotidien. Semiologie du fait divers. Anthro pos, París, 1973, reed. 1983. 
la que introdúí la inseguretat com a tema polític. D'això a atribuir-la a Giscard d'Estaing només hi ha un pas, ben fàcil de realitzar tan bon punt hom vegi clar el benefici que qualsevol poder -i no només un poder de dretes $i$ un poder d'Estat - pot obtenir de la inseguretat. Tan sols cal recordar que en el domini del fet polític, la tesi del complot és el camí més curt $\mathbf{i}$ més decisiu per a eliminar tota mena d'anàlisi.

\subsection{L'EXPTICACIÓ PER LA CRISY}

La crisi té el mèrit de presentar-se com una causalitat abstracta i de garantir així la recerca d'un cap de turc. Si aconseguíssim caracteritzar adequadament de quina menta de crisi es tracta, estaríem sens dubte en presència d'un candidat ben seriós per a explicar la inseguretat. En boca d'aquells que avancen aquest argument —en general són militants polítics o sindicals- es tracta tan sols de la crisi econòmica i l'argumentació reposa en una triple equació:

$$
\text { Crisi }=\text { atur }=\text { delinquència }=\text { inseguretat. }
$$

Deixant de banda l'anàtisi del valor de les dues primeres, apuntarem només que l'última és de nour l'explicació mitjançant la delinquiència, i que la cadena no representa aitra cosa que una versió d'aquesta explicació rectificada per a desculpabilitzar els delinqüents.

\subsection{ETCÈTERA}

La llista no acaba aquí, fins $i$ tot si només ens atenim al que és públic. Però la presentació d'aquesta successió d'explicacions, donada la seva seriacio, planteja el veritable problema: el de la possibilitat d'explicar el fenomen. Una competència tan gran d'anàlisis torna aquestes possibilitats una mica irrisòries. El terreny esdevé equívoc ja que d'aquesta manera apareix saturat d'explicacions que es neutralitzen quan entren en contacte.

Aquest equívoc planteja aleshores un dilema al sociòleg: ¿quina funció pot assignar, dins d'aquest àmbit, al seu discurs? ¿Privilegiarà una explicació en detriment de les altres? ¿Afegità a aquesta sèrie la seva pròpia explicació? En ambdós casos només aconseguirà engrossir la sobrecàrrega i contribuir a la cacofonia. Fins i tot si l'explicació sociològica és argumentada sobte una base conceptual més afinada i fonamentada en un tractament més tigorós de les dades, no pot evitat d'entrar en competència 
amb les altres, és a dir, no pot aparèixer sinó com un element d'allò que vol explicar. Cal trobar, per tant, una forma de procedir que tingui en compte aquest fet primer de l'equívoc del terreny estudiat. Veurem que això equival al renunciament de l'explicació.

\section{EL DISCURS INSEGURITZADOR}

Totes les explicacions que hem revisat són discursos sobre la inseguretat, situant el fenomen exteriorment en relació amb el subjecte de l'enunciació. ¿Quina és, en relació amb aquest primet registre, l'especificitat del discurs inseguritzador, el discurs del subjecte que diu viure la inseguretat? ${ }^{4}$

Allo que sorprèn a primera vista en aquests enunciats és llur caràcter exorbitant, la utilització d'imatges crues, l'afirmació peremptòria de solucions radicals, la imputació tot ras; és un discurs que no pateix cap mena de contradicció. És també, a la seva manera, un discurs sociològic, però que ve marcat pel segell del seu origen popular. És un discurs «ben de casar, que parla per a aquell que ha crescut a França en contacte amb el poble $o$ amb el carrer, donades les seves múltiples refetències o allusions a un cos de màximes, de proverbis constitutius del sentit comú.

Malgrat aquesta dimensió una mica pintoresca no es pot amagar per molt de temps: 1) Que aquest discurs desenvolupa una argumentació unificada $i$ coherent. 2) Que aquesta argumentació no reprèn cap de les explicacions avançades anteriorment sobre el fenomen. 3) Que els incidents delictius hi juguen un paper secundari $i$, podtíem dir-ne, retòric. 4) Que no retrobem mai aquest discurs en la premsa.

Essencialment es tracta d'un judici de la política penal de l'Estat, del seu caràcter liberal, o més encara, del fet que aquesta política està centrada en el problema de la delinqüùncia. Esquematitzant l'argument, podem dir que aquest reposa sobre el teorema següent: si l'Estat es preocupa pels bandarres («voyous»), per excusar-los, per desculpabilitzar-los, per atenuar el rigor del càstig, per reinserir-los, etcètera, se situa en llut terteny, que no és el de la gent honesta; mentre treballa per la inclusió dels que són fora de la llei, el poder exclou aquells que en són dins.

4. Elements d'aquest discurs han estat tecollits durant l'enquesta sobre l'autodefensa feta en 1979-1980 i durant la realitzada sobre la inseguretat (en collaboració amb Wernet Ackermann i Henxi-Pierte Jeudy) en 1980-1981. Cf. Renaud Dulong: L'autodéfense, enquête sur quelques foits indécidables. Librairie des Méridiens, París, 1983. Capitol 3: «Le discours de l'autodéfense». 
En aquest context caldria subratllar tres punts. Primerament, la particular concepció de la llei que es pot deduir d'aquestes formulacions. La Ilei apareix com una entitat suprahumana que s'imposa fins i tot a l'Estat; al mateix temps, hom li assigna com a única feina la garantia de la propietat privada; és la llei la que fonamenta un ordre de petits propietaris. D'altra banda, el caràcter neuràlgic de la fallida de la llei per a aquells que la denuncien. L'exorbitància de les paraules i la violència de les imatges no són un efecte d'estil, sinó que ens indiquen que allò que està en joc concerneix la gent d'una manera totalment crucial. Per últim, aquesta virulència és encara més perniciosa car l'argument acaba desembocant en l'autodefensa: l'Estat ja no exerceix adequadament el monopoli de la violència legítima i esdevé legítim que les comunitats locals o els individus se'n facin càrrec. El balanç d'aquesta substitució de l'Estat per l'individu és, a França, molt greu: una cinquantena de morts, més d'un centenar de ferits.

La presentació esquemàtica d'aquest discurs tha simplificat moltíssim i ha atenuat, en concret, les patinades fantàstiques que acompanyen la seva forma desorbitada. Per exemple, és si més no sorprenent veure com Ia figura del delinqüent, segons la caracterització del terme «bandarra» (voyou), desapareix tot deixant la seva plaça de cap de turc a la figura del nen. ${ }^{5}$ Uns altres trets subratllen que, a despit de la temàtica única que el sosté, aquest discurs és molt equívoc. El problema és saber, seguint la línia desenvolupada fins aquí, si aquest equívoc té alguna cosa a veure amb el precedent, amb aquell que es derivava de la multidimensionalitat dels discursos politics sobre la inseguretat.

Com a mínim podem trobar-hi una relació, la qual clarifica singularment el repte epistemològic que la inseguretat planteja al sociòleg. L'afany d'explicació seria símptoma d'una incapacitat per a rebre aquest altre discurs a causa de la seva exorbitància i de la seva indecència. Però també ens indicaria que aquest discurs toca de prop quelcom que està en joc i que és realment neuràlgic des del punt de vista de la societat política. Aquest diluvi d'explicacions tendiria a ofegar la virulència: amb la pretensió de reemplaçar amb una anàlisi racional allò que és rebut com un crit, s'evi. taria haver d'analitzar-lo precisament en el marc de l'afirmació política d'una incapacitat de l'Estat per a mantenir un ordre moral $i$, per tant, un ordre social.

El projecte d'una sociologia de la inseguretat esdevé així encara més problemàtic. En el marc d'aquesta batalla d'eslògans i d'arguments veiem massa clar el que significaria, per exemple, una anàlisi de la inseguretat en termes de determinants sòcio-econòmiques. El sociòleg és presoner d'una

5. Id., capitol 5: «L'enfant qui métite la mort». 
xarxa significativa que preexisteix a la seva mirada. En aquest tema les exigències d'objectivitat i de neutralitat que especifiquen un discurs amb pretensions científiques són pervettides pel lloc que l'Estat ocupa en aquesta batalla d'arguments. Una sociologia que abordés el fenomen des d'una orientació positivista només sabria inscriure's en el marc de la societat política, tot participant en el treball de repressió de la queixa popular o, si més no, desviant el procés que la gent en va intentar d'obrir.

\section{IA NO EXPLICAR, SINO COMPRENDRE}

Interpellat d'aquesta maneta per un judici que concerneix tots els membres de la societat, el sociòleg es veu obligat a reflexionar sobre allò que fa, sobre allò que diu, sobre la seva pretensió de produír arguments més vàlids, sobre la posició que el seu discurs implica dins d'un terzeny con. flictiu, etc. Aquesta forma de procedir té evidentment valor per ella mateixa, però, en el cas que ens ocupa, ha de conduir a solucions concretes: Què fer? Què dir? Corn dir-ho? A qui dir-ho?

Només proposem aquí les dues «solucions» al problema amb caràcter provisional i per a donar a conèixer una forma d'actuar que és encara a les beceroles. Aquestes solucions consisteixen en una renúncia a l'explicació en sociologia per a instaurar unes altres maneres de fer, comprendre d'una banda, descriure de l'altra. En l'exposició de la idea insistirem menys en les referències teòriques als corrents de pensament que han fecundat aquesta manera de treballat que no pas en les implicacions pràctiques que aquestes alternatives comporten des del punt de vista d'una sociologia de la inseguretat.

Si treballem des de la perspectiva d'una sociologia comprensiva, començant per la primera de les dues alternatives, sento la necessitat d'indicar, d'una manera més personal, que aquesta mena de sociologia s'ha imposat no tant per una simpatia envers Max Weber i la tradició filosòfica alemnanya de l'hermenèutica com per una exigència més pragmàtica lligada a la redacció de l'obra final de la meva investigació sobre l'autodefensa: tenia acumulada una gran quantitat de notes d'enquesta i em calia presentarles com un text sociològic. Més enllà de les qüestions d'estil, de la manera d'escriure, una quiestió em semblà decisiva: ¿qui seria el subjecte de l'enunciació? ¿Desapareixeria com ho fa en la majoria de la literatura sociològica? ¿O el discurs indicaria, ben al contrari, gràcies a l'ús de la primera persona del singular, el seu origen concret, la seva producció per un individu situat 
socialment, culturalment, etcètera ${ }^{6}$ Urgit per la necessitat de respondre a aquestes preguntes vaig buscar l'opinió d'aquells que ja s'ho havien plantejat en un altre context. Això explica, per una banda, que, si les meves referències van des de Weber fins a Gadamer, en tant que han treballat els considerants filosòfics d'aquest problema, estic en deute sobretot amb Jeanne Fravret-Saada, una etnòloga francesa que s'ha interessat per la bruixeria que encara existeix al departament de la Mayenne, perquè la seva experiència serveix de base per a Ia meva, si no en les solucions que cal adoptar, sí, com a minim, en els obstacles que cal evitar. ${ }^{2}$ Quant al tema de la redacció d'una obra sobre la bruixeria, elia denuncia pertinentment, crec, l'etnografa clàssica i el pensament postestructuralista francès wen llur ideal comú de total atopia del subjecte que teoritzas.8 Més prosaicament, tot adoptant el «ío» per donar compte de la seva investigació, assexyala -en un to que em sembla autèntic- - que hom no pot parlar de bruixeria si no ha estat "pres» ell mateix pel procés de llenguatge que es desenvolupa en ella.

Adoptar una perspectiva comprensiva té, per tant, la implicació ptàctica següent: del fet que el discurs mantingut per aquells que diuen viure la inseguretat divideix l'àmbit social, es deriva imperativament la necessitat que el sociòleg enuncii el punt d'aquest àmbit, així delimitat, des del que enunciarà el seu discurs. Aquest principi pot ésser argumentat a partir de tesis epistemològiques que ens remeten a corrents de pensament coneguts -no podem parlar de la societat serse adoptar un punt de vista dins de la societat, la sociologia dels altres no és mai totalment impertinent, la sociologia no és res més que un element del fenomen que vol explicar, etc....-, però un cop més aquest argument ens ve imposat per la urgència i només ha descobert els seus referents teòrics, així com les seves implicacions èticopolítiques quan ja era massa tard. I ha estat tant el producte d'una reflexió sobre el material com el resultat d'una disquisició epistemològica. El moment decisiu d'aquesta forma de procedir ve donat pel reconeixement del fet que l'adopció d'un estil impersonal - -ja sigui acadèmic, científic o simplement descriptiu - situava el discurs com a un producte de la societat política. Aquest teconeixement no és el resultat d'una crítica de la funció política del saber sociològic i de l'exemplaritat del positivisme dins d'aquesta funció de justificació de l'statu quo social, sinó que apareix després d'una reflexió espectulativa sobre el discurs periodístic, ja que aquest oferia l'exemple d'allò que podia ésser un discurs sobre la inseguretat. Ara bé, l'expres-

6. Cf. «On ne peut parler de l'autodéfense qu'à la première personne du singuliet» a «Problèmes d'épistémologie en Sciences Sociales», núm. II CEMS, 1983.

7. Jeanne Favret-Saada: Les mots, la mort, les sorts. Gallimard, París, 1978.

8. Ibid., p. 29. 
sió pexiodústica del fenomen eza també una expressió distanciada, una producció d'exterioritat, una objectivació dessimplicant; especificava l'heteronomia de la por en la seva fixació en un punt concret del conjunt social -els seus baixos fons - $i$ circumscrivia la seva pertinença a aquest punt. Tot plegat ho trobem en les narracions d'autodefensa, en els editorials sobre la inseguretat, en els reportatges sobre la violència urbana com si hom hi pogués assistir fent una abstracció de tota l'emoció que provoquen i bana* litzant llur dimensió escandalosa. No només no es deixa parlar massa els actors - llur discurs és sens dubte més perillós que no pas indecent-- sinó que s'estigmatitzen llurs paraules en uns termes que neutralitzen llur dimensió «política», és a dir, Lur capacitat de plantejar problemes que concerneixen tothom, començant per la persona mateixa que escriu.

En definitiva la postura periodística és condemnable en el sentit que anulla o exclou tota mena de relació amb aquells dels quals vol donar compte i en el sentit que reforça l'exclusió de la qual aquests se senten víctimes a causa d'un discurs que neutralitza llur queixa. Ara bé, de tot el que hern anat dient fins aquí - amb tot, ben poca cosa! - se'n deriva que el discurs inseguritzador qüestiona la historicitat d'aquells que el mantenen, que és una avaluació del canvi social, que és una forma de descripció de la relació amb llur societat, és a dir, una ideologia. Una anàlisi més distanciada permet fàcilment el refús d'aquesta trascendència política. Pel mateix motiu, prepata $i$ coprodueix la sordesa respecte dels blancs més específics d'aquesta revolta: eis magistrats, els governants, els polítics, els intelliectuals, és a dir, tota la societat política.

Per tant, ¿calia restituir purament i simplement les formulacions recollides en la investigació i fer desaparèixer ei sociòleg darrera de l'actor? Aquí, un cop més, obviarem les consequiencies metodologiques (refús de tota especificitat en l'acte sociològic) i ètiques (garantia de legitimació de l'autodefensa) per insistir en l'obstacle pràctic que fa que el projecte esdevingui insostenible. Presentat el discurs inseguritzador tan cruament com el recull l'enquesta és establir que aquest discurs pot passar tal com és de la situació en la que ha estat enunciat --tot sovint no com a resposta a l'investigador, sinó més aviat al marge de la seva presència- a la inscripció en les pàgines d'una obra. Toquem potser aquí el punt més problemàtic del nostre procediment, aquell en el que s'articula una anàlisí política i una reflexió sobre el llenguatge. La dificultat per a produir una versió escrita del discurs sobre l'autodefensa ens ternet immediatament a la seva forma d'expressió oraí, a les formes poc polides que fa servir, a la indecència del seu lèxic, a l'absència d'articulació interproposicional, etc... Es tracta d'un problema de forma més que no pas de contingut. Però aquest problema de forma es deriva del fet que es tracta d'un discurs produit i reproduït en 
els canals de la comunicació popular quotidiana - converses de bar, xafarderies entre veïnes- que escapen totalment de l'esfeta de la política, la qual és també d'alguna manera, l'esfera de l'escriptura."

Malgrat tot, aquests dos punts de vista no esgoten el camp definit pel discurs de la inseguretat i podem definir com a mínim dos punts més, deslligats dels anteriors: el del delinqüent $i$ el del testimoni. Aquest últim és el que ha definit finalment la solució del problema. Per dues taons, una d'autenticitat, l'altra de fecunditat. Perquè la veritable situació del sociòleg de la inseguretat no és pas la d'ésser delinquient, ni defensor de l'autodefensa, ni policia, ni magistrat, ni governant, però sí que és la d'aquell que se sent evidentment afectat per un fenomen que transforma en aquest sentit el seu paisatge social amb la disseminació d'aparells de protecció, amb la multiplicació de gossos policies $i$ de vigilants $\dot{i}$ amb la banalització de l'autodefensa, etc... I és alhora la situació en la qual el terreny assoleix el seu màxim grau d'equívoc, ja que no queda cap altre mitjà per a explicar el fenomen que el d'identificar-se - posar-nos en llur lloc- amb aquells que se senten amenaçats, és a dir, ocupar un altre punt de l'àmbit. En la redacció de l'obra sobre l'autodefensa aquesta postura queda illustrada per dues idees: d'una banda, el sociòleg s'assigna la tasca d'aclarir el malestar que ell mateix sentia quan llegia les històries de lladres assassinats per Hurs víctimes $\mathbf{i}$, d'altra banda, descobreix que, de la llista dels protagonistes de l'autodefensa, l'únic amb el que es pot identificar és la víctima innocent d'alguna espifiada. ${ }^{10}$

Des d'aquesta situació el sociòleg pot fer jugar els discursos els uns en relació amb els altres $i$, tot posant en joc la seva pròpia historicitat, donarlos un sentit diferent. Pot produir quelcom que ja no pertany a l'àmbit del coneixement sinó al de la veritat, donat que eis peròs que eludeix per plan. tejar la seva intexpretació ja no pettanyen a l'àmbit de la falsedat, sinó al de la superxeria.

Analitzant el contingut, el que descobreixo en el discurs inseguritzador és una postura envers el carvi social, en el sentit d'una certa nostàlgia. Els que l'experimenten parlen de l'ordre social com si en fossin orfes. Ata bé, aquest enunciat m'interpelia en tant que membre de la societat política, perquè comparteixo corn a tal l'herència del racionalisme, implantat pel

9. Malgrat tot, una gran part de la temàtica entorn de ia inseguretat circula en forma escrita en les cartes que la gent s'adreça quan es projecten milícies municipals, quan es realitzen actes d'autodefensa, etc. Aquestes cartes ens han permès, d'altra banda, una anàlisì més precisa d'aquesta temàtica mostrant-nos sinuacions produïdes fora de la demanda del sociöleg. Exigitien, per tant, un comentari més elaborat sobrc larticulació entre l'escriptora i la societat política.

10. Op. cit, p. 23. 
segle de les llums, segons la qual el canvi s'explica amb paraules com progtés, emancipació, llibertat. Quan es tracta del canvi dels costums - car la referència a la llei no designa cap altra cosa-- petcebo que la positivitat de la que induïm l'evolució de la societat, en l'esfera de la paraula pública, s'acaba pagant raturalment amb la destrucció i la mort. L'aporema consisteix, per tant, en la incapacitat de pensar dialècticament el canvi històric, que, és d'una manera indissociable, alhota, inauguració i enterrament. Puix que la majoria silenciosa -wl'expressió té un sentit per a mi ja que he pogut sentir el que es prontncia darreta d'aquest silenci- no aconsegueix de trobar una expressió d'aquest scntiment en el registre del discurs oficial, el fustiga amb pràctiques de mort.

\section{IA NO EXPLICAR, SINO DESCRIURE}

Aquesta alternativa serà presentada més breument ja que només existeix sota la forma d'esbós. La seva presentació voldria subratllar aquí que la postura que acabem de definir no és pas exclusiva, $i$ que el sociòleg potser no és tan presoner del camp de la inseguretat com sembla. Renunciar a l'explicació no implica necessàriament el tancament en una accepció hermenèutica del treball sociològic, amb tots els riscs de subjectivisme que una definició de la investigació com aquesta comporta. Aquest segon plantejament -segon en tant que ofereix la possibilitat d'altres sortides-recolza en dos moments de la investigació, el primer dels quals ha consistit en el tractament automàtic d'una part del material recollit al llarg de l'enquesta sobre l'autodefensa," el segon és la confrontació dels problemes plantejats per les particularitats de l'àmbit amb la problemàtica de l'etnometodo. logia..$^{12}$

Es tracta bàsicament d'agafar al peu de la lletra allò que hem enunciat des del començament d'aquest text, és a dir, que la inseguretat només se'ns presenta com a discurs sociològic. Sí la inseguretat és sociologia, ¿per què no l'estudiem amb la mateixa cura amb què estudiem l'obra dels nostres collegues? Després de tot, som capaços de donar compte de la sociologia d'Alain Touraine o de Talcott Parsons, sense patlar d'autors de menys importància, i no és difícil entendre què és el que impediria adoptar la mateixa actitud respecte a les produccions dels nostres contemporanis que no Leon.

11. Analyse automatique du Discours reaitzat per Michel Pecheux i Jacqueline

12. «L'ethnométhodologie en premiète approximation». Text de treball del Seminari de la Universitat Autònoma de Barcelona dels dies 27 i 28 de març de 1984. 
es defineixen com a membres de la comunitat dels sociòlegs, però que no són pas menys sociòlegs, com a membres de la societat, per a ocupar-se dels afers d'aquesta, conzentar-los, explicar-los $i$, amb aquesta producció de sentit, sostenir l'existència d'aquesta societat.

Realment, no podem legitimar aquest refús argumentant una falta de competència dels enunciadors del discurs inseguritzador o d'aquells que intenten explicar-lo. No podem negar que la recuperació i el reciclatge dels conceptes sociològics - - ja que tothom, en la insegutetat, parla de societat, de classes, de poder, de marginalitat, etc...- separen aquests conceptes de lluts sistemes sintàctics $i$ els assignen un altre abast. Per tant no podem a priori excloure que aquest bricolage de nocions no tingui tant de sentit com les nostres manipulacions expertes, sobretot quan coneixem a quina mena de pràctiques dóna lloc aquest bricolage.

Disposaríem així d'una altra definició de l'acte d'investigació, que tindria, respecte a la precedent, el mèrit de sotmetre aquest acte a la regulació d'un control collectiu: explicitar els procediments de llenguatge gràcies als quals la gent fabrica la inseguretat, tot explicant les narracions de tobatoris o agtessions, comentant llurs efectes, analitzant llurs causes, explicant el context en el que la gent dóna sentit a les seves formulacions, etc... Res. pecte a l'equívoc que caracteritza l'àmbit, i que esdevé un bon barem per a avaluar la pertinència de les aproximacions, ja no es tractaria de guanyar punts de suport per a descobrir nous significats, sinó de donar compte de la producció d'aquest equívoc, de la seva fabricació, ja que aquest equívoc, tepeteixo, no és res més que el fruit d'un procés d'elaboració.

Per assenyalar que ja s'han produit uns primers avenços en els intents de fer un treball més rigorós sobre les dades, indiquem un dels resultats de l'anàlisi automàtica. L'estudi de les recurrències morfo-sintàctiques dóna validesa en gran mesura al «teorema» amb el qual hem tesumit anteriorment la temàtica del discurs inseguritzador. L'estudi del loc dins del discurs del seu subjecte d'enunciació fa aparèixer, per variació paradigmàtica, una sèrie de cercles concèntrics al voltant del «jo» - jo, jo $\mathrm{i}$ els meus béns, jo i la meva família, el nostre poble, tots els municipis, tota Françaque separen els poca-vergonyes («voyous»), per un cantó, de l'esfera estatal, per l'altre.

Les orientacions etnometodològiques ofereixen una relació ben difetent entre les dades d'investigació, en la mesura que imposen la no-comprensió d'allò que ha estat dit independentment del context, i l'assignació del sentit a partir d'allò que un membre participant en la situació en pot comprendre. Un examen pragmàtic com aquest de les dades permet explicitar, per exemple, de quina manera la gent comprèn l'entrevista amb un sociòleg $\mathrm{i}$ 
negocia amb ell el sentit de les seves preguntes $i$ de les seves respostes. ${ }^{\mathrm{J}}$

Per acabar aquesta revisió una mica cadtica del problema de la inseguretat, ens agradaria tornar al punt descobert de passada que potser no és especiffc de la inseguretat. Quan manifestàvem la irreductibilitat del discurs sobre la inseguretat a les explicacions oficials del fenomen, potser no hem insistit prou sobre la revisió que aquest discurs imposa respecte a les iHusions d'una transparència lingüística de la societat per al sociòleg. Perquè nosaltres comencem la investigació amb la idea que, a qualsevol lloc de la societat, ens és possible comprendre al peu de la letta - abans d'interpretar-ho amb els nostres esquemes d'anàlisi- allo que es diu. Només acceptem excepcions per a llengües minoritàries o per als argots. La sordesa dels polítics respecte al discurs sobre la inseguretat fou reconeguda al llarg de la investigació com a sordesa del sociòleg: es veié obligat, per a poder comprendre, a utilitzar procediments de localització de tecurrències lexicals i temàtiques que hom fa servit quan ha d'aprendre una liengua estrangera. Podem interpretar com a resistència aquesta primera inaudibilitat del discurs, però contra què actua exactament aquesta resistència? ¿Contra el contingut -que, és cert, vehicula bastants fantasmes mottífers per a hortoritzar- o contra el reconeixement d'aquesta desorbitància dels jocs de llenguatge que relativitza les capacitats d'investigació del sociòleg $i$, alhora, subratlla la seva solidaritat amb la institució? Sigui com sigui, una expe. riència com aquesta demostra que l'autonomia de la societat civil respecte a l'Estat és també una autonomia lingüística i que l'accés del sociòleg als continguts de sentit que circulen pels canals inframediatics de la comunicació quotidiana no és en absolut immediat.

(Traducció del trancès de Mercè Filella.)

13. Cf. un article que apareixerà en el núm. III de Problèmes d'Episténologie en Sciences Sociales, consagrat a l'etnornetodologia. 



\title{
CURSO SOBRE «EL DEBATE SOBRE CORPORATIVISMO. NEOCORPORATISMO. APLICACION A ESPAÑA» (27 al 30 marzo 1984)
}

\author{
Organización: ICE, Universidad de Barcelona \\ Coordinación: Carlota Solé, Universidad de Barcelona
}

A través del Instituto de Ciencias de la Educación de la Universidad de Barcelona se organizó un curso para tratar del debate internacional sobre las nuevas formas de integración de intereses en las sociedades avanzadas, las formas de acuerdo entre asociaciones tepresentativas de fuerzas sociales (sindicatos, patronal) con el Estado (administración, gobierno) y su plasmación en pactos concertados, de ámbito estatal, etc. Desde la Segunda Guerra Mundial, no sólo están presentes o persisten aspectos de ideología corporativa, característica de los tegímenes fascistas, en las sociedades capitalistas que operan como democracias al estilo liberal; sino que surger estructuras políticas cuyas formas institucionales y premisas de operatividad refiejan rasgos corporativos existentes en la Italia y la Alemania de los años treinta.

El neocorporativismo es un modelo de sociedad para algunos estudiosos del tema. Para otros es un modo de producción que sustituiría al capitalista. Para unos tercetos autores es simplemente una estructura política en el seno del capitalismo. En cualquier caso, se ha convertido en un enfoque útil para estudiar la forma en que los intereses de distintos grupos sociales, que en principio son antagónicos (a saber, obreros, empresarios y Estado), interactúan y quedan tramados en una red tripartita de intereses. La simbiosis tripartita de intereses de los cuerpos de admiristración del Estado, sindicatos y asociaciones empresariales, configura una práctica política, de recurrente actualidad en las sociedades avanzadas, en la época de crisis que comienza a mediados de la década de los setenta (1974, aproximadamente). 
La distinción entre el viejo corporatismo (fascista) y el nuevo corporatismo, corporatismo estatal y societal, autoritario y liberal, es aplicable al caso de España, en la época en que la crisis económica mundial afecta profundamente a la economía española, por un lado; y por otro, en un período de despertar democrático en que se legalizan los sindicatos y los empresarios se asocian bajo nuevas reglas y normas de convivencia y negociación con el Estado. El debate sobre tneocorporativismo tiene interés en su aplicación a España para definir o interpretar una nueva situación de creciente estabiliłdad democrática, basada en los acuerdos tripartitos entre el Estado, los sindicatos y Ias organizaciones empresariales, como sistema de intermediación de intereses, más allá del pluralismo y el parlamentaris" mo. El debate tiene interés hoy, a principios de 1984, por cuanto comien" za a recrudecerse la conflictividad laboral, al haberse roto muchas de las negociaciones (sobre convenios, acuerdos salariales, condiciones de trabajo, etcétera) entre las partes interesadas (sindicatos, patronal) y no existir gatantía de cumplimiento de los acuerdos establecidos (Pacto de la Moncloa, ANE, etc.). El interrogante sobre la viabilidad del neocorporatismo o neocorporativismo como forma de intermediación de intereses y de negociación de conflictos está abierto.

Estas cuestiones generales fueron analizadas sistemáticamente por Philippe Schmitter, cuyo axtículo publicado en 1974 («¿Aún en el siglo del corporatismo $\gg$ ) centró el debate y es punto de referencia obligado para cualquier discusión sobre el tema. Ph. Schmitter bizo una brillante exposición de los conceptos básicos sobre el neocorporatismo englobando tres preocupaciones recurrentes de la filosofia política: la representación de los ciudadanos, el proceso de toma de decisiones y la organización del Estado y su control sobte Ia población. Después de distinguir entre neocorporatismo como autoorganización de la sociedad civil (es decir, cómo los grupos sociales que reconocen sus intereses formales se organizan) y como método de toma de decisiones e implementación de las mismas por la administra. ción (prsblic decision making), explicó por qué emergió el tema y el fenómeno del neocorporatismo y cuáles han sido las subteorías que han derivado de su aparición. Seguidamente expuso las líneas de investigación que actualmente se siguen en el análisis del corporatismo en sus diversas versiones y grados de desarrollo.

La segunda sesión, del día 28 de matzo de 1984, corrió a cargo de Wolfgang Streeck, colaborador de Philippe Schmitter en un proyecto internacional en el que se comparan las prácticas neocorporativas en diversos sectores industriales de once países europeos y los USA. W. Streek habló de las formas que toman las relaciones industriales neocorporativas como sistema específico de relaciones industriales; de las tazones por las que los 
actores sociales principales han estado interesados en entrat y llevar a cabo prácticas corporativas, razones que se centran en los beneficios económicos que obtienen empresarios y obreros en una estructura corporativa; cómo aparece el sistema de relaciones industriales corporativas y cómo mantiene su estabilidad; cuáles son los problemas económicos que surgen, y de ellos, cuáles son solucionables y cuáles no, a fin de llegar a la estabilidad. La definición de sistema de relaciones industriales corporativas que dio Streeck fue la de que selementos significativos de la relación de empleo son regulados al nivel central, es decir, más allá y por encima de las empresas individuales; entre los sindicatos y las organizaciones empresariales, ambos monopolísticos y centralizados, sobre el proceso de regulación y los resultados del mismo, que son tratados como cuestión de intetés público por parte de los agentes estatales». Se trata pues de una organización específica de los actores involucrados: una estructura organizativa corporativa. Ejemplos de aplicabilidad de esta definición se pueden hallar en Austria, Suecia, Alemania occidental, Noruega, y Finlandia en algunos aspectos.

De algunos de estos países, en concreto, de Suecia, Alemania e Inglaterta, habló de nuevo W. Streeck en el curso de la mesa redonda que se organizo en la tercera sesión del curso. Los dos primeros países, de larga experiencia en acuerdos neocorporativos contrastan con la situación de Inglaterra, donde es impensable un pacto social en la actualidad. $\mathrm{Ph}$. Schmitter se refirió al caso de Italia, donde en los dos últimos años se han producido sorprendentemente pasos importantes en la tendencia hacia prácticas corporativas. La sorpresa estriba especialmente en el cambio de actitud de uno de los sindicatos más importantes, la CGL, de orientación comunista, que se negaba secularmente a establecer acuetdos sectoriales con la patronal, ampliando su ámbito de protección a los intereses de grupos sociales que pueden beneficiarse de medidas como la escala móvil de salarios. La unión de los tres sindicatos más importantes en Italia en una «supraconfederación» actuando en algunos sectores como el del metal, por una parte, y por otra, en la segunda mitad de la década de los años setenta, el «compromiso histórico» a nivel de partidos políticos, por el cual el partido comunista se convirtió en un miembro de facto del gobierno, en cuestiones de legislación labotal, fueron dos factores importantes a tener en cuenta para entender el acuerdo social «desde y por arriba» hacia la base de los sindicatos y organizaciones empresariales. En cierto sentido representa históricamente la vía inversa (a la de los Países Escandinavos, por ejemplo) hacia el corporatismo. La idea de scambio politico, o intercambio político entre las élites gubernamentales, sindicales y empresariales refleja fidedignamente esa realidad. Manuel de Lucena se refirió al caso de Portugal como ejemplo de "corporativismo», en línea de continuidad con 
ia tradición ideológica salazarista. Igualmente, Juan Martínez Alier desarrolló en su exposición los síntomas de la tendencia clata hacia acuerdos neocorporativos en la época de transición democtática abierta en España desde la legalización de los partidos políticos y de los sindicatos en 1977 1978 , a pesar de los altibajos de los acuerdos que las fuerzas sociales ban establecido.

Terminó el curso con la sesión a cargo de W. Streeck y Ph. Schtnitter sobre la relación entre democracia y corporatismo. La cuestión central se plantea del siguiente modo: el neocorporatismo actúa en contra de la democracia, eliminando las formas de representación tradicionales, la libertad de asociación; de forma que se aleja cualquier posibilidad de monopolizar o imponer el poder político. El neocorporatismo viene a ampliar esa con. cepción clásica de democracia, como arte de asociación entre grupos sociales que se organizan temporalmente, al apuntar de forma tealista, a la permanencia de esos grupos sociales organizados que continúan actuando asociativamente. Por otro lado, la actividad de las asociaciones hará dectecer el peso del Estado, según la concepción Tocquevilliana de la democracia. $Y$, sin embargo, se constata la importancia creciente del Estado en las sociedades avanzadas. Esas dos razones dan pie a pensar que la organización de los intereses no es necesariamente un componente de la democracia. El necorporatismo transforma el principio liberal de asociabilidad voluntaria en una concentración de participación en determinadas asociaciones, a la vez que éstas disminuyen en número. La elección libre deja de set significativa para dejar paso a la defensa colectiva de la sociedad civil.

La participación en el curso fue numerosa y contó con la presencia de estudiosos del tema, procedentes de Córdoba, Madrid y Barcelona. AI término de cada sesión, el coloquio y la discusión fueron únicamente interrumpidos por las obligaciones de horario. El próximo año 1985 se celebratá en Barcelona el meeting de la ECPR (Consorcio Europeo de Investigación en Ciencia Política). Los días previstos son: del 25 al 30 de marzo. Será una buena ocasión para volver a intercambiar información y estudiar el terna del neocorporatismo. 